\title{
СТУДЕНЧЕСКИЕ СТАРТАПЫ В ВУЗАХ РОССИИ: СОВРЕМЕННАЯ СИТУАЦИЯ
}

\author{
(c) 2021 Петров Антон Маркович \\ кандидат экономических наук, доцент, ведущий научный сотрудник, \\ Научно-исследовательский институт развития образования \\ Российский экономический университет имени Г. В.Плеханова, Россия, Москва \\ E-mail: petrov-am2000@yandex.ru
}

\begin{abstract}
Осуществление студентами предпринимательской деятельности является сегодня распространённым явлением в мире. Кроме того, в настоящее время все большее внимание уделяется развитию стартапов, которые созданы и управляются студентами, что подтверждает материал данной статьи. Есть много способов превратить университетские технологии и инновации в факторы экономического развития: создание компании - один из них. Сегодня во всем мире ожидается, что университетские стартапы станут источником дальнейшего развития. Многие российские университеты создали уникальную комплексную систему поддержки студенческого предпринимательства.
\end{abstract}

Ключевые слова: студенческое предпринимательство, стартап, бизнес, экономика, университеты.

Введение. В современных условиях, как показывает зарубежная и российская практика, высшие учебные заведения выполняя наряду с традиционными функциями (образовательная, т.е. осуществление подготовки высококвалифицированных специалистов по образовательным программам высшего образования, а также научная, т.е. проведение исследований по различным тематикам, которые могут иметь для науки и общества как фундаментальное, так и прикладное значение) активно реализуют еще и функцию экономического характера, которая, в частности, включает: коммерциализацию результатов академической науки; вывод на рынок наукоемкой продукции и управление интеллектуальной собственностью с целью получения прибыли; создание новых бизнесов, в том числе через предпринимательскую активность студентов. В современных условиях университеты в мире преобразуются из учебных заведений в особые экосистемы («инкубаторы»), в которых развивается и активно применяется интеллектуальный потенциал молодежи для трансформации общества и обеспечения его в качестве важного фактора экономического роста государства [15, с. 197]. Следовательно, современный университет, выполняя экономическую функцию, становится важным участником в создании и развитии экосистемы территории, на которой он находится. В этой связи в вузах возрастает роль в проведении непрерывной и комплексной работы с проектными командами студентов и стартапами, которые образуются на базе универси- тетов. Для этого в российских вузах, особенно в ведущих, ведется не только развитие проектного обучения, открытие образовательных программ и проведение различных образовательных курсов по предпринимательству, но и организуется консультационное, методическое и иное сопровождение студенческих предпринимательских проектов за счет создания и деятельности на базе университетов специальных структурных подразделений (бизнес-инкубатора, проектного офиса, университетского акселератора и др.) [4, c. $15,28,66]$. Кроме того, развитие молодежного предпринимательства, активное создание стартапов на базе вузов в России становятся ключевыми направлениями государственной политики, темой обсуждения на разных уровнях власти.

Сегодня можно встретить разные взгляды на содержание «стартапа» (startup). Так, к примеру, стартап можно рассматривать как временную структуру, которая занимается поисками масштабируемой, воспроизводимой, рентабельной бизнес-модели. Поначалу шаблон бизнес-модели стартапа состоит из идей и догадок. Однако, с нахождением рентабельной бизнес-модели, рынка для реализации продукции (услуг), источника финансирования происходят изменения, в том числе осуществляется оформление бизнеса и последующий рост его масштаба [10, с. 29]. Стартапами обозначают еще молодые компании, которые были основаны для разработки и реализации уникального продукта или услуги. Стартапы, основываясь на инновационных идеях, осуществляют устранения недо- 
статков у существующих продуктов, процессов или создают полностью новые категории товаров и услуг, тем самым кардинально изменяя укоренившиеся способы мышления и ведения бизнеса для целых отраслей. Поэтому сегодня стартапы можно рассматривать в отраслях их деятельности в качестве источников революционных изменений, что доказывает, к примеру, такие реализованные широко известные проекты: Facebook, Apple, Netflix, Google и многие другие. Следовательно, ключевыми особенностями, которые отличают стартапы от других компаний: стартап стремится создать совершенно новый шаблон бизнеса; стартапы стремятся очень быстро не только реализовать идеи, но и расширить свою клиентскую базу, т.е. их отличает еще и скорость и рост [14].

Как показывает обширная практика, не только финансовые ресурсы важны для развития стартапов, но и работа команды их основателей, в том числе по продвижению товаров, услуг новообразованного бизнеса и позиционированию зарождающего бренда (это требует поиска и использования соответствующих инструментов маркетинга [2]).

Результаты исследования. Отметим, что в 2021 году, который объявлен в Российской Федерации «Годом науки и технологий», со стороны органов государственной власти выдвигаются предложения и предлагаются системные решения, которые призваны обеспечить ускорение участия университетов в экономическом развитии страны, в том числе за счет участия вузов в технологическом и ином обновлении отраслей.

В 2021 году планируется за счет реализации программы стратегического академического лидерства «Приоритет-2030» (Постановление Правительства Российской Федерации от 13.05.2021 № 729) сформировать в России широкую группу высших учебных заведений, которые должны стать лидерами в формировании нового научного знания, технологий и разработок для внедрения в российскую экономику и социальную сферу. Данная программа направлена на решение целого блока национальных задач в сфере развития образования, науки и технологий [8], в том числе позволяющих университетам обеспечить: развитие и внедрение высоких технологий в жизнедеятельность людей и в различные отрасли хозяйственного комплекса страны; развитие и успешную реализацию личностного потенциала (самореализацию) людей, в том числе, как мы считаем, посредством создания студентами и учёными стартапов.

Важными трендами для университетов в современных условиях является не только обеспечение интеграции научных школ и ученых высших учебных заведений с бизнес-сообществом и промышленным сектором экономики, вовлечение талантливых студентов в инновационный процесс создания наукоемкой продукции для последующего ее внедрения в реальный сектор экономики, но также еще и создание инновационного пояса стартап-компаний вокруг вузов [13, с. 413]. Поэтому логика обучения «от курсовой работы к проектной разработке по заказу работодателя, а от нее - к стартапу» начинает входить в практику все большего числа образовательных программ вузов [6, с. 147]. В данной ситуации становится вполне закономерным, что на высшем уровне государственной власти России отмечается необходимость развития в университетах страны системы поддержки молодежного предпринимательства. Так, к примеру, Председатель Правительства РФ Михаил Мишустин в ходе посещения 12 апреля 2021 г. Московского авиационного института (национальный исследовательский университет) отметил в своем выступлении, что «стартапы, подход технологический к стартапам должен быть серьёзно инкорпорирован в систему нашего высшего образования. Стартап в этом смысле может быть темой дипломной работы» [3]. Кроме того, Председателем Правительства РФ была отмечена необходимость создания в университетах школ стартапов [7]. Поэтому логическим продолжением предложений стало то, что Правительством РФ была одобрена инициатива по развитию платформы студенческого предпринимательства и ее включения в национальный проект «Наука и университеты» [3]. Отметим, что реализация такой правительственной инициативы в стране должна обеспечить координацию деятельности органов власти, университетов, а также иных заинтересованных организаций в поддержке развития студенческого предпринимательства. За счет наращивания у студентов компетенций и практических навыков в части предпринимательской деятельности, изучения и масштабирования лучших практик вузов по содействию созданию студенческих стартапов и т.п. планируется активизировать творческий потенциал студентов, обеспечить рост инновационного предпринимательства в стране и развитие но- 
вой бизнес-элиты.

С целью поддержки молодёжного предпринимательства в стране Министерство науки и высшего образования Российской Федерации, в свою очередь, подготовило проект Постановления Правительства России «Об утверждении Правил предоставления грантов в форме субсидий из федерального бюджета на оказание государственной поддержки студий студенческого технологического предпринимательства («стартап-студий»)». В проекте данного нормативно-правового акта указывается, что: под студией студенческого технологического предпринимательства («стартап-студия»)» понимается структурное подразделение организации или хозяйственное общество, которое создается в форме МИПа, на базе образовательной организации высшего образования, доля которой в уставном капитале составляет не менее двадцати шести процентов, с целью выявления и развития предпринимательских компетенций студентов и аспирантов образовательной организации высшего образования в научнотехнологической сфере, вовлечения предпринимателей в развитие наукоемких проектов, создаваемых на базе образовательных организаций с участием студентов и аспирантов, содействия в формировании, привлечении финансирования и реализации стартапов (бизнес-проектов), в том числе, за счет средств специализированных фондов. При этом, как отмечается в данном проекте, «стартап (бизнес-проект)» следует рассматривать как особую форму проекта с короткой историей деятельности (способная существовать и без образования организационно-правовой формы), которая направлена на тестирование бизнес-идей и гипотез с целью формирования нового бизнеса или достижения социального эффекта. Исходя из общей концепции документа следует, что основная деятельность стартапов заключается в создании инновационных продуктов (товаров, технологий, услуг или процессов), поиске партнеров и потребителей на них, а также привлечении финансовых ресурсов для обеспечения устойчивых и масштабируемых бизнес-моделей.

Следует обратить внимание на то, что по идеи разработчиков проекта нормативного документа гранты, которые будут предоставляться на трехлетний период по результатам проведения конкурсов (в заявках предельный размер гранта, на который может претендовать орга- низация, не должна превышать 30 миллионов рублей на финансовый год), должны обеспечить создание и развитие на базе образовательной организации высшего образования функциональной стартап-студии. Разработчики проекта определяют в документе не только порядок проведения конкурса, условия соглашения о предоставлении гранта, перечень направлений расходов средств гранта, но и обязательства организации по привлечению еще и внебюджетных средств в объеме не менее $25 \%$ от суммы гранта в первый год, $50 \%$ - во второй год и $75 \%$ в третий год. При этом, как отмечено в проекте, внебюджетные средства могут включать как средства организации в денежной форме, так и денежные средства из внешних источников финансирования. Таким образом, государство устанавливает не только размер софинансирования мероприятий по созданию и развитию стартап-студии, но и определяет, как мы считаем, необходимость уже с первого года выдачи гранта поиска и привлечения вузами еще и внешних партнеров (фирм, финансовых организаций и т.п.). Кроме того, интерес вызывает еще группа показателей, по которой будут оцениваться результаты грантополучателей: количество бизнес-проектов (стартапов), подготовленных студентами организаций в рамках деятельности стартап-студий» (единиц); число студентов организаций, вовлеченных в деятельность стартап-студий (человек); число студентов организаций, защитивших выпускную квалификационную работу в формате «стартап как диплом» (человек) [1]. Как мы считаем, данную группу показателей можно расширить количественной оценкой юридически оформленных стартапов (общее число созданных компаний и зарегистрированных ИП) и/или долей стартапов (от сформированных в стартап-студии за календарный год), которые вышли на рынок и смогли начать реализацию своих услуг (товаров).

Практика показывает, что многие известные и успешные стартапы зародились в университетах (к примеру: в Стэнфордском университете - социальная сеть и мессенджер Snapchat; в МФТИ - сервис Skyeng) [11]. Поэтому сегодня в целях повышения предпринимательской активности у молодежи в вузах России поэтапно реализуется программа «Стартап как диплом», которая направлена на вовлечение талантливых студентов в развитие экосистемы технологического предпринимательства, а также на 
поддержку бизнеса, находящегося на начальной стадии. Отметим, что разработка и реализация программы обучения абитуриентов и преподавателей университетов в подготовке стартапов в качестве выпускной квалификационно работы определены в национальной государственной программе «Цифровая экономика». В целях реализации данного направления государственной политики в документе определена необходимость реализации ряда мероприятий: начиная от проведения обучающих тренингов и заканчивая оказанием целенаправленной консультационной помощи студентам в реализации их бизнес-проекта. В целом, как определяется сегодня государственными нормативными актами, стать участникам программы «Стартап как диплом» может обучающийся любого направления подготовки, специальности и уровня образования. Однако, необходимо чтобы студент в команде стартапа соответствовал роли и соответствующим функциональным обязанностям, что доказывается за счет освоения им необходимых компетенций, которые определены в конкретных ФГОС ВО или ОС ВО. И студенты, и большинство российских вузов еще только «осваивают» данную возможность, оценивают открывающиеся для них перспективы.

Отметим, что впервые в пробном режиме данная программа стартовала в 2017 году в Дальневосточном федеральном университете. С 2021 года, как отмечается на сайте Минобрнауки России, планируется внедрение практики учета выпускных квалификационных работ в виде стартапов уже в более чем 40 вузах страны [12]. Следует обратить внимание, что в настоящее время студенты, которые решат воспользоваться такой возможностью, могут представить стартап в качестве своей выпускной квалификационной работы как уже в форме работающего бизнеса, т.е. реализованного бизнес-проекта (наличие юридического лица и сформированной командой), так и в форме только проработанной идеи будущего бизнеса, что может послужить еще одним стимулом для реализации молодежью предпринимательских инициатив.

По данным мониторинга Минобрнауки России в 2019/20 учебном году в рамках реализации в стране программы «Стартап как диплом» прошли защиты в вузах более трехсот соответствующих выпускных квалификационных работ. Кроме того, Минобрнаукой России отмечается, что за рассматриваемый период времени наиболее популярными сферами тематики выпускных работ в вузах страны были не только оказание различных услуг, в том числе открытие интернет-магазинов, но и создание и реализация информационных технологий, включая нейронные сети, искусственный интеллект и облачные технологии. Из всех презентованных стартап-проектов, защищенных в качестве выпускных квалификационных работ в рамках программы «Стартап как диплом» к реализации, как отмечается на сайте Минобрнауки России, вышли 38\% - это 117 проектов. Из них 54 проекта смогли заинтересовать и привлечь в свое развитие инвестиционные средства [9], что доказывает их привлекательность и перспективу их развития.

В настоящее время университеты в России, стремясь обеспечить предпринимательскую активность молодежи, развивают не только сам образовательный процесс, механизм вовлечения в него представителей бизнес-сообщества, но и создают у себя организационную инфраструктуру комплексной поддержки проектной работы студентов, работы студенческих команд над идеями бизнес-проектов и оформлениями их в стартапы. Каждый вуз привносит свою уникальную практику в эту систему. Так, к примеру, в Университете «Синергия» студент на защиту выпускной работы в качестве стартапа должен обязательно представить выписку из ЕГРЮЛ, что является доказательством регистрации (необходимо провести за несколько лет до самой защиты) и текущей деятельности своего бизнеса [5]. В свою очередь, за счет реализации и развития в РЭУ им. Г.В.Плеханова целенаправленных обучающих, консультационных, конкурсных и иных мероприятий у все большего числа студентов вуза происходит формирование предпринимательского мышления, что ведет к росту интереса обучающихся вуза к вопросу о возможности создания собственного бизнеса, а также к подготовке выпускных квалификационных работ в форме стартапа.

В целом, как мы считаем, программа «Стартап как диплом» стала не только дополнительным стимулом для талантливых и активных студентов, но и стала новым инструментом для университетов в работе со студентами.

Таким образом, в современных условиях в России, как показывает практика развитых стран мира, требуется формирование политики вузов, которая должна быть ориентирована 
на развитие предпринимательства за счет не только соответствующего обучения, проведения исследований в данной области, оказания консультационных услуг (наставничество для начинающих бизнес-команда), но и за счет создания так называемых предпринимательских университетов, с развитой, в том числе, инфраструктурой поддержки и развития молодежного предпринимательства, с активным взаимодействием с местным бизнесом, органами власти, инновационными и венчурными институтами, с активным участием в предпринимательских сетях и сообществах [16].

Заключение. Сегодня университеты служат важной площадкой для формирования студенче- ских команд, которые разрабатывают бизнес-идеи и трансформируют их в бизнес-проекты, а далее в стартапы, которые через время могут стать новыми направлениями бизнеса. Поэтому передовые вузы осуществляют формирование у себя системы по: оценке потенциала студентов и студенческих команд в качестве предпринимателей, бизнес-идей в качестве возможного бизнеса; предоставлению студентам дополнительных современных практических знаний в области предпринимательской деятельности; пошаговому развитию стартапов, созданных студентами, в том числе по поиску ими партнеров и выводу продукта (услуги) на рынок.

\section{Библиографический список}

1. Проект Постановления Правительства Российской Федерации «Об утверждении Правил предоставления грантов в форме субсидий из федерального бюджета на оказание государственной поддержки студий студенческого технологического предпринимательства («стартап-студий»)» (подготовлен Минобрнауки России 30.03.2021) [Электронный ресурс]. - 2021 - Режим доступа: http:/www.garant.ru/products/ipo/prime/ doc/56772665/\#ixzz70tJQHEUU дата обращения: 12.07.2021).

2. Ваничева Е. А. Маркетинг-инструмент обеспечения устойчивого развития стартапа // Экономические науки. 2017. № 148. C. 51-55.

3. Валерий Фальков: Стартапы и акселераторы должны быть рядом со студентами [Электронный ресурс]. - 15 апреля 2021 - Режим доступа: https://minobrnauki.gov.ru/press-center/news/? ELEMENT_ID=32478 (дата обращения: 15.07.2021).

4. Инновационная экономика и технологическое предпринимательство: комплекс методических материалов по практическим работам для слушателей курса. Авторы-составители: А. Гусев, М. Казакова, А. Крицын, Ю. Логачев, А. Николаев, М. Руденко, Д. Чашкина, П. Черкашин, М. Эрман. Научный редактор - Н. Митюшин. Под редакцией Р. Ступина, А. Семенова. Москва: RIS Ventures. 2018. 267 с.

5. «Интерфакс» представил рейтинг лучших образовательных программ по предпринимательству вузов России [Электронный ресурс]. - 22 апреля 2021 - Режим доступа: https://academia.interfax.ru/ru/news/ articles/6430/ (дата обращения: 25.05.2021).

6. Казакова Е.И. Университет как субъект обновления содержания образования. В книге: Три миссии университета: образование, наука, общество / Ред. кол.: В. А. Садовничий и др.- Москва: МАКС Пресс. 2019.440 с.

7. Михаил Мишустин посетил Московский авиационный институт [Электронный ресурс]. - 12 апреля $2021-$ Режим доступа: http://government.ru/news/41943/ (дата обращения: 01.07.2021).

8. Программа «Приоритет-2030» [Электронный ресурс].-2021.- Режим доступа: https://minobrnauki.gov.ru/ action/priority2030/ (дата обращения: 15.07.2021).

9. Программа «Стартап как диплом» запускается в 25 новых субъектах Российской Федерации [Электронный ресурс]. - 20 февраля 2021 - https://minobrnauki.gov.ru/press-center/news/? ELEMENT_ID=29635 (дата обращения: 25.06.2021).

10. Стартап: настольная книга основателя / Стив Бланк, Боб Дорф; Перевод с английского.- М.: Альпина Паблишер. 2013. 616 с.

11. Стартап-экосистемы в вузах [Электронный ресурс]. - 12 января 2021 - Режим доступа: https://minobrnauki. gov.ru/press-center/news/? ELEMENT_ID=27610 (дата обращения: 15.07.2021).

12. Стартап как диплом [Электронный ресурс]. - 20 ноября 2020 - Режим доступа: https://minobrnauki.gov.ru/ press-center/news/? ELEMENT_ID=25900 (дата обращения: 25.06.2021).

13. Сыдыков Е.Б. Евразийский национальный университет имени Л.Н.Гумилева: евразийский образовательный ландшафт миссии университета. В книге: Три миссии университета: образование, наука, общество / Ред. кол.: В.А. Садовничий и др.- Москва: МАКС Пресс. 2019. 440 с. 
14. Baldridge R., Curry B. What is a Startup? [Electronic resource]. - April 1, 2021 - Available at: https://www.forbes. com/advisor/investing/what-is-a-startup/ (Retrieved: 10.07.2021).

15. Dorofeeva $V$. $V$. Opportunities for universities to use the German experience in the startup ecosystem development // International conference Germany and Russia: Ecosystems without borders. [Electronic resource]. - 2021.Available at: https://iopscience.iop.org/article/10.1088/1755-1315/689/1/012015/pdf (Retrieved: 15.06.2021)

16. Novak O., Musiichuk S., Zuenko S. Management culture: the role of university startups // Naukovyi Visnyk Natsionalnoho Hirnychoho Universytetu. 2020. № 5. Pp. 193-198. 